\title{
LA SUPERACIÓN DEL MONOPOLIO PROTECCIONISTA DE LOS DERECHOS HUMANOS EN EL ESTADO CONSTITUCIONAL MEXICANO, A PARTIR DE LA REFORMA AL ARTÍculo PRIMERO CONSTITUCIONAL*
}

\author{
OVERCOMING PROTECTIONIST \\ MONOPOLY OF HUMAN RIGHTS IN THE \\ MEXICAN CONSTITUTIONAL STATE, \\ AFTER THE AMENDMENT TO THE FIRST \\ ARTICLE OF THE CONSTITUTION
}

\author{
Alejandra Flores-Martínez** \\ Enrique Uribe-Arzate $* * * *$ \\ Fecha de recepción: 27 de marzo de 2014 \\ Fecha de aceptación: 30 de abril de 2014 \\ Disponible en línea: 30 de julio de 2014
}

\section{Para citar este artículo/To cite this article}

\begin{abstract}
Flores-Martínez, Alejandra \& Uribe-Arzate, Enrique, La superación del monopolio proteccionista de los derechos humanos en el estado constitucional mexicano, a partir de la reforma al artículo primero constitucional, 129 Vniversitas, 103-133 (2014). http://dx.doi.org/10.11144/Javeriana. VJ129.smpd

doi:10.11144/Javeriana.VJ129.smpd
\end{abstract}

* Trabajo producto del proyecto de investigación El neoconstitucionalismo mexicano en materia de derechos humanos: retos para lograr un verdadero garantismo constitucional, financiado por la Secretaría de Educación Pública en México.

** Doctora en derecho por la Facultad de Derecho, Universidad de Zaragoza, España. Miembro del Sistema Nacional de Investigadores, Nivel I. Correo electrónico: licale_23@hotmail.com

*** Doctor en Derecho por la Facultad de Derecho, Universidad Nacional Autónoma de México. Miembro del Sistema Nacional de Investigadores, Nivel II. Correo electrónico: euribea@ uaemex.mx 


\section{RESUMEN}

En este trabajo se estudia la incidencia normativa entre la Constitución y los tratados internacionales para la efectiva tutela de los derechos humanos en México, a partir de la reforma constitucional del 10 junio de 2011 y la paradigmática sentencia de la Suprema Corte de Justicia de la Nación en el expediente varios 912/2010. Con estos cambios, los criterios internacionales se convierten en parámetro interpretativo rompiendo con el único y último intérprete de los derechos humanos. Desde el enfoque epistemológico de este trabajo, la apertura constitucional mexicana a la protección internacional de los derechos humanos genera un control externo y una doble garantía para estos derechos, que escapa de criterios unilaterales o reduccionistas nacidos de la voluntad exclusiva del Estado; es decir, se trata de un diálogo recíproco entre los órganos jurisdiccionales internos e internacionales que busca superar el monopolio proteccionista de los derechos humanos en México.

Palabras clave: Derechos humanos; diálogo jurisprudencial; interpretación constitucional; reciprocidad normativa, monopolio interpretativo. 


\section{ABSTRACT}

This paper studies the incidence of the Constitution and international treaties for the effective protection of human rights in Mexico, after the constitutional reform of June 10th 2011 and the paradigmatic sentence of the Supreme Court of Justice of the Nation within the file varios ('various') 912/2010. With these changes, international criteria become an interpretive parameter that end the sole and final interpretation of human rights. Based on an epistemological approach, the Mexican constitutional openness to the international protection of human rights builds an external control and a double guarantee for such rights, which extends beyond reductionist or unilateral criteria from the exclusive will of the State; that is to say, there is a reciprocal dialogue between domestic and international judicial bodies that seeks to overcome the protectionist monopoly in relation to human rights in Mexico.

Key words: Human rights; jurisprudential dialogue; constitutional interpretation; reciprocity rules; interpretive monopoly.

\section{SUMARIO}

Introducción.- I. AnteCedentes.- II. InCidencia nORMativa ENTRE LA CONSTITUCIÓN Y LOS TRATADOS INTERNACIONALES DE DERECHOS HUMANOS.- III. DiÁLOGO ENTRE TRIBUNALES CONSTITUCIONALES Y ÓRGANOS INTERNACIONALES PROTECTORES DE DERECHOS humanos.- IV. LA PERSPECTIVA DEL DiÁlogo MEXiCANO.- ConClusiones.- Bibliografía. 


\section{INTRODUCCIÓN}

Para introducirse en el estudio del tema que se propone es pertinente reconocer, en principio, la insuficiencia del ordenamiento interno para la tutela de los derechos fundamentales. Tal situación, quedó en evidencia al término de la Segunda Guerra Mundial, cuando surgió la "manifestación cultural —en lo filosófico, en lo político y en lo jurídico- del consenso generalizado en torno de los derechos del hombre" ", es decir, la Protección Internacional de los Derechos Humanos. A partir de este momento, por voluntad de los Estados se ha conformado paulatinamente un orden internacional para la protección de los derechos humanos por medio de los tratados internacionales. No obstante lo anterior, la principal consecuencia es que los tratados internacionales generan el reconocimiento jurídico de órganos internacionales con jurisdicción y competencia para la protección de los derechos humanos. Ahí se sitúa la interconexión normativa que da lugar a la metaconstitucionalidad recíproca.

Los tratados internacionales acarrean obligaciones para los Estados y estos reconocen en sus Constituciones una fuente del Derecho Internacional como fuente interna. Por tanto, se gesta un reconocimiento interno de las normas internacionales protectoras de derechos humanos y de los órganos encargados de velar por su cumplimiento. Con ello, tiene lugar una incidencia normativa entre el orden interno e internacional para la debida tutela de los derechos humanos mediante dos documentos jurídicos por antonomasia: la Constitución y los tratados internacionales de derechos humanos.

En cierto modo, esto genera el llamado neoconstitucionalismo, que en palabras de Comanducci está caracterizado por lo que él denomina una "Constitución invasora"; además por la positivización de un catálogo de derechos fundamentales, por la omnipresencia en la Constitución de principios y reglas y por algunas peculiaridades de la interpretación y de la aplicación de las normas constitucionales, respecto a la interpretación y aplicación de la ley². Además, se postula que los contenidos constitucionales no son cerrados ni

1 Germán Bidart-Campos, Teoría general de los derechos humanos, 415, Astrea, Buenos Aires (1991).

2 Paolo Comanducci, Formas de (neo)constitucionalismo: un análisis metateórico, en Neoconstitucionalismo(s), 75-98, 83, Miguel Carbonell, coord., Trotta, Madrid (2009). 
atienden exclusivamente la voluntad de los poderes públicos internos, sino están abiertos a otros contenidos metaconstitucionales, debido a que la propia norma constitucional fija un puente con las normas internacionales.

El presente artículo tiene como objetivo analizar si el reconocimiento mutuo antes referido produce un diálogo entre los operadores jurídicos nacionales e internacionales para la protección de derechos humanos y si hay claros parámetros para entablar ese diálogo en México a partir de la reforma integral en materia de derechos humanos de junio de $2011^{3}$. La hipótesis de esta investigación busca explicar los supuestos con que opera el diálogo jurisprudencial al ser una operación argumental recíproca entre las Cortes que está auspiciada por el método comparativo. Este método implica un contraste normativo y no un injerto injustificado de contenidos internacionales. Además, se considera que no está en tela de juicio la aplicabilidad de la norma constitucional, sino simplemente fijar su contenido.

El artículo comienza haciendo alusión a los antecedentes en México para delimitar el objeto de investigación y la importancia de problematizar la situación en nuestro país, después se aborda la incidencia normativa entre la Constitución y los tratados internacionales para ubicar en tiempo y espacio la superación del monopolio estatal para la protección de los derechos humanos. En el marco conceptual se establecen los elementos del diálogo jurisprudencial por medio de la praxis de cortes internacionales, se estudian los criterios sentados en sus sentencias y las doctrinas europea y latinoamericana para finalmente, centrar el análisis en el caso mexicano mediante el examen de la dogmática mexicana vertida después de la reforma aludida y la sentencia de la Suprema Corte de Justicia de la Nación en el expediente varios 912/2010.

3 Decreto 117, LXI Legislatura, por el que se modifica la denominación del Capítulo I del Título Primero y reforma diversos artículos de la Constitución Política de los Estados Unidos Mexicanos, 10 de junio de 2011. Disponible en: http://www.diputados.gob.mx/LeyesBiblio/ legis/reflxi.htm 


\section{ANTECEDENTES}

En México, con la reforma al artículo primero constitucional del 10 de junio de 2011 se inició el llamado neoconstitucionalismo mexicano al contemplar una cláusula de apertura al Derecho Internacional de los Derechos Humanos que rompió con el monopolio interpretativo de los órganos jurisdiccionales internos y constitucionalizó los estándares internacionales. La reforma introdujo al texto constitucional lo siguiente:

Artículo 1o. En los Estados Unidos Mexicanos todas las personas gozarán de los derechos humanos reconocidos en esta Constitución y en los tratados internacionales de los que el Estado mexicano sea parte, así como de las garantías para su protección, cuyo ejercicio no podrá restringirse ni suspenderse, salvo en los casos y bajo las condiciones que esta Constitución establece.

Las normas relativas a los derechos humanos se interpretarán de conformidad con esta Constitución y con los tratados internacionales de la materia favoreciendo en todo tiempo a las personas la protección más amplia4.

En este panorama subyace un reconocimiento mutuo entre el Estado y los órganos internacionales que denota la preocupación por tutelar de forma efectiva los derechos humanos. En este sentido, se supondría que cuando se legisla, se interpreta o se decide un conflicto entre derechos humanos, los operadores internos tienen como parámetro los criterios internacionales, debido a tres causas jurídicas principales:

1. Los tratados forman parte del ordenamiento jurídico y constituyen obligaciones internacionales para el Estado (Artículo 133 de la Constitución mexicana ${ }^{5}$ y artículos 26 y 27 de la Convención de Viena sobre el derecho de los tratados $)^{6}$.

4 Decreto 117, LXI Legislatura, por el que se modifica la denominación del Capítulo I del Título Primero y reforma diversos artículos de la Constitución Política de los Estados Unidos Mexicanos, 10 de junio de 2011. Disponible en: http://www.diputados.gob.mx/LeyesBiblio/ legis/reflxi.htm

5 Constitución Política de los Estados Unidos Mexicanos, 5 de febrero de 1917. Disponible en: http://www.ordenjuridico.gob.mx/constitucion.php, http://www.ordenjuridico.gob.mx/ Constitucion/cn16.pdf

6 Organización de Naciones Unidas, ONU, Convención de Viena sobre el derecho de los tratados, suscrita en Viena, Austria, 23 de mayo de 1969, entró en vigencia el 27 de enero de 1980. Disponible en: http://www.wipo.int/export/sites/www/wipolex/es/glossary/vienna-convention-es.pdf 
2. Los tratados, según mandato constitucional, sirven de referente interpretativo de los derechos fundamentales (Artículo 1 de la Constitución mexicana).

3. Todas las autoridades — en el ámbito de sus competencias — tienen la obligación de promover, respetar, proteger y garantizar los derechos humanos (Artículo 1 de la Constitución mexicana, artículos 1 y 2 de la Convención Americana sobre Derechos Humanos) ${ }^{7}$.

De esta manera, el monopolio para la protección de los derechos humanos se rompe, debido a que todas las autoridades tienen la obligación de proteger estos derechos. El monopolio cerrado para la interpretación es rebasado, a pesar de que la jurisprudencia mexicana postula que corresponde a la Suprema Corte de Justicia de la Nación, como máximo intérprete de la Constitución Federal, fijar la jurisprudencia que debe prevalecer $^{8}$. Sin embargo, todo indica que en cuanto a derechos humanos se refiere los órganos jurisdiccionales mexicanos ya no son los únicos intérpretes, sino que la doctrina de los órganos internacionales contribuye de forma sustancial para fijar el contenido constitucional de estos derechos.

De esta forma, con la sentencia del expediente varios 912/2010, la Corte mexicana dejó de lado el criterio jurisprudencial sobre la inexistencia del control difuso de la constitucionalidad, al ser atribución exclusiva del Poder Judicial de la Federación ${ }^{9}$. La Corte abandonó este criterio y apostó por el control difuso de convencionalidad, decisión que reconoce la calidad de protectores de los derechos humanos, plasmados en la Constitución y en los tratados internacionales, a todos los jueces nacionales ${ }^{10}$. No obstante todo lo anterior, la interrogante que surge es: ¿realmente hay un diálogo

7 Organización de Estados Americanos, OEA, Convención Americana sobre Derechos Humanos o Pacto de San José, CADH, San José, Costa Rica, 7-22 de noviembre de 1969. Disponible en: http://www.oas.org/dil/esp/tratadosB-32ConvencionAmericanasobreDerechosHumanos.htm

8 México, Suprema Corte de Justicia de la Nación, tesis jurisprudencial XXVIII, de julio de 2008. Disponible en: https://www.scjn.gob.mx/libreria/Novena2011Docs/julio.pdf

9 México, Suprema Corte de Justicia de la Nación, tesis jurisprudencial P./J. 74/99 de agosto de 1999. Disponible en: http://www.jurisconsulta.mx/index.php/JurisprudenciaSCJN/ ViewTesis?iD=198397

10 Eduardo Ferrer-Mac-Gregor, Interpretación conforme y control difuso de convencionalidad. El nuevo paradigma para el juez mexicano, en La reforma constitucional de derechos humanos, un nuevo paradigma, 339-429, 429, Miguel Carbonell \& Pedro Salazar, coords., Porrúa, México (2012). Disponible en: http://biblio.juridicas.unam.mx/libros/7/3033/14.pdf 
entre los órganos jurisdiccionales mexicanos y los órganos internacionales?

Y en caso de que la respuesta fuera positiva: ¿en qué supuestos y cómo se hace?

De entrada, la respuesta a la pregunta inicial es que no hay un diálogo jurisprudencial en México. La Corte alimenta un monopolio interpretativo $\mathrm{y}$, a pesar de las últimas reformas, aún está en espera de sentencias condenatorias para accionar y proteger derechos humanos. La Suprema Corte mexicana sigue sosteniendo criterios reduccionistas para la protección de los derechos humanos al considerar solamente obligatorios los criterios de la Corte Interamericana de Derechos Humanos fijados en sentencias condenatorias y ha dejado de lado la doctrina vertida en otros asuntos y, por supuesto, de otros órganos internacionales.

Para robustecer esta postura, vale la pena explicar la incidencia normativa entre la Constitución y los tratados internacionales, y plantear por medio de la jurisprudencia internacional cómo germina un diálogo en beneficio de una mayor protección a los derechos humanos.

\section{INCIDENCIA NORMATIVA ENTRE LA CONSTITUCIÓN Y LOS TRATADOS INTERNACIONALES DE DERECHOS HUMANOS}

Para enfocar el punto central de esta investigación, es conveniente analizar la creciente incidencia normativa entre los ordenamientos interno e internacional. Esta incidencia abarca dos aspectos: por un lado, la existencia de cláusulas constitucionales de apertura internacional; por otro, fuentes internacionales que reconocen los ordenamientos constitucionales y toman sus postulados como límite de sus especificaciones. En el primer rubro, encontramos las siguientes cláusulas constitucionales:

1. Cláusulas europeas implícitas o explícitas. Conforme el proceso de integración europea avanza, las Constituciones de los Estados miembros incorporan las denominadas cláusulas europeas, disposiciones específicas destinadas a hacer viable, desde la perspectiva constitucional nacional, la pertinencia a la Unión en los 
diferentes estadios en los que el referido proceso de integración se ha encontrado ${ }^{11}$ (verbigracia: Constitución española artículo 93, Constitución de Alemania, artículos 23, 24 y 25).

2. La aplicación del bloque de constitucionalidad a tratados internacionales de derechos humanos (Constitución de Argentina artículo 75; Constitución de Colombia artículo 93; Constitución de Guatemala artículo 46; la Constitución Austriaca por reforma del año 1964 otorga al Convenio Europeo de Derechos Humanos el mismo rango que la Ley Fundamental de 1867 y el resto de normas constitucionales internas relativas a Derechos Fundamentales).

3. Reconocimiento de los tratados internacionales como canon hermenéutico de los derechos fundamentales (Artículo 16, inciso 2 de la Constitución de Portugal; artículo 10.2 de la Constitución española; artículo 93 de la Constitución de Colombia de 1991; artículo 13 de la Constitución de Bolivia de 2009; artículo 84 de la Constitución de Ecuador de 2008; la cuarta disposición transitoria de la Constitución Peruana de 1993 y; en el artículo 1 de la Constitución mexicana).

Como ejemplo de fuentes internacionales que indican el respeto a los ordenamientos constitucionales está el artículo 4 del Tratado de Lisboa que dispone:

2. La Unión respetará la igualdad de los Estados miembros ante los Tratados, así como su identidad nacional, inherente a las estructuras fundamentales políticas y constitucionales de estos, también en lo referente a la autonomía local y regional...

La Convención Americana sobre Derechos Humanos refiere en el artículo segundo, que los Estados adoptarán con arreglo a sus procedimientos constitucionales las medidas legales o de otro carácter que fueren necesarias para hacer efectivos tales derechos y libertades. En el mismo tenor, se expresa el Pacto Internacional de Derechos Civiles y Políticos que señala que los Estados se comprometen a adoptar, con arreglo a sus procedimientos constitucionales,

11 Pedro Cruz-Villalón, La Constitución inédita. Estudios sobre la constitucionalización de Europa, 140, Trotta, Madrid (2004). 
las medidas oportunas para dictar las disposiciones legislativas o de otro carácter que fueren necesarias para hacer efectivos los derechos. Estas cláusulas denotan que los tratados internacionales parten del supuesto de respetar los ordenamientos constitucionales para hacer efectivos los derechos.

Luego entonces, en esta interconexión hay un reconocimiento mutuo e incluso conforme a la línea argumental de Pedro CruzVillalón y Giusseppe de Vergottini, la interconexión normativa entre las Constituciones y los tratados internacionales de derechos humanos es una especie de enriquecimiento mutuo que se visualiza en contenidos mínimos y en estándares comunes a todos los Estados $^{12}$. Se trata de un proceso con doble etapa: una constitucionalización de criterios internacionales y una internacionalización de contenidos constitucionales.

Ahora bien, la teoría neoconstitucional manifiesta que la incidencia normativa da lugar a una metaconstitucionalidad recíproca para la protección de los derechos fundamentales. Este fenómeno se explica como una nueva realidad que la teoría constitucional debe asumir $^{13}$. Refiriéndose a Europa, Jürgen Schwarze opina que hay un incremento del nivel de reciprocal interaction between national and European constitutional law ${ }^{14}$. Para Joaquín Brage-Camazano, progresivamente se configura una parte sustantiva del Derecho Constitucional Común Europeo (si nos enfocamos en Europa $)^{15} \mathrm{y}$ para Peter Häberle es un Derecho Constitucional Común ${ }^{16}$. De la misma manera, la doctrina del Derecho Común Europeo manifiesta un modelo constitucional que combinaría cuatro elementos: una referencia al federalismo, el Estado de Derecho y la reserva de ley, la

12 Pedro Cruz-Villalón, La Constitución inédita. Estudios sobre la constitucionalización de Europa, 140, Trotta, Madrid (2004).

13 Vlad Constantinesco, ¿Hacia la emergencia de un derecho constitucional europeo?, 8 Cuadernos Constitucionales de la Cátedra de Fadrique Furió-Ceriol, Valencia, 5-17, 10-11 (1994).

14 Jürgen Schwarze, The Birth of a European Constitutional Order, 16, Nomos Verlagsgesellschaft, Baden-Baden (2001).

15 Joaquín Brage-Camazano, Ensayo de una teoría general sustantiva de los Derechos Fundamentales en el Convenio Europeo de Derechos Humanos, en Integración Europea a través de derechos fundamentales: de un sistema binario a otro integrado, 113-145, 123, FrANCISCO JAVIER García-Roca \& Pablo Antonio Fernández-Sánchez, coords., Centro de Estudios Políticos y Constitucionales, CEPC, Madrid (2009).

16 Peter Häberle, Derecho Constitucional Común Europeo, 79 Revista de Estudios Políticos, Madrid, 7-46, 7 (1993). Disponible en: http://dialnet.unirioja.es/servlet/listaarticulos?tipo_ busqueda=ANUALIDAD\&revista_busqueda=1166\&clave_busqueda=1993 
justicia constitucional y el respeto de los derechos fundamentales ${ }^{17}$. Para Gustavo Zagrebelsky, se trata de una "justicia constitucional cosmopolita"18. Mientras que para la doctrina latinoamericana es la Constitucionalización del Derecho Internacional ${ }^{19}$, un ius commune interamericano en materia de derechos humanos ${ }^{20}$ y la nacionalización del derecho internacional de los derechos humanos ${ }^{21}$.

La teoría de la metaconstitucionalidad recíproca descansa sobre la idea de que los derechos humanos son bienes comunes a todos los Estados Constitucionales; a los tratados internacionales de derechos humanos subyace un sistema de valores y principios de alcance universal ${ }^{22}$. También hay sentencias que califican los tratados de derechos humanos como instrumentos constitucionales del orden público internacional ${ }^{23}$; así mismo, se estipula la obligación de las autoridades nacionales como guardianes de tratados internacionales en esta materia ${ }^{24}$. Además, no se olvide que precisamente a los

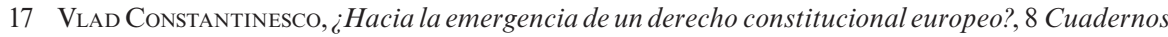
Constitucionales de la Cátedra de Fadrique Furió-Ceriol, Valencia, 5-17, 9 (1994).

18 Gustavo Zagrebelsky, El juez constitucional en el siglo XXI, 10 Revista Iberoamericana de Derecho Procesal Constitucional, México, 249-267, 249 (2008). Disponible en: http://biblio. juridicas.unam.mx/libros/6/2725/7.pdf

19 Eduardo Ferrer-Mac-Gregor, Interpretación conforme y control difuso de convencionalidad. El nuevo paradigma para el juez mexicano, en La reforma constitucional de derechos humanos, un nuevo paradigma, 339-429, 357, Miguel Carbonell \& Pedro Salazar, coords., Porrúa, México (2012). Disponible en: http://biblio.juridicas.unam.mx/libros/7/3033/14.pdf

20 Héctor Fix-ZAMudio, Breves reflexiones sobre el concepto y el contenido del derecho procesal constitucional, en Derecho Procesal Constitucional, 165, Eduardo Ferrer-Mac-Gregor, coord., Porrúa, Colegio de Secretarios de la Suprema Corte de Justicia de la Nación, México (2002). Juan Carlos Hitters, Control de constitucionalidad y control de convencionalidad. Comparación. Criterios fijados por la Corte Interamericana de Derechos Humanos, 7 Estudios Constitucionales, Chile, 2, 109-128, 109 (2009). Disponible en: http://www.scielo.cl/pdf/estconst/ v7n2/art05.pdf. NéSTOR Pedro SAGüÉs, El control de convencionalidad como instrumento para la elaboración de un ius commune interamericano, en La justicia constitucional y su internacionalización: ¿hacia un ius constitutionale commune en América Latina?, tomo II, 449-468, 449, Armin von Bogdandy, Eduardo Ferrer-Mac-Gregor \& Mariela Morales-Antoniazzi, coords., Universidad Nacional Autónoma de México, UNAM-Max Planck Institut, México (2010). Disponible en: http://biblio.juridicas.unam.mx/libros/6/2895/15.pdf

21 Diego García-SAYÁn, Una viva interacción: Corte Interamericana y Tribunales Internos, en La Corte Interamericana de Derechos Humanos. Un cuarto de siglo: 1979-2004, 324-384, 325, Editorial Corte Interamericana de Derechos Humanos, San José, Costa Rica (2005). Disponible en: http://www.corteidh.or.cr/docs/libros/cuarto\%20de\%20siglo.pdf, http://www.corteidh. or.cr/tablas/diego_06.pdf

22 A modo de ejemplo, Tribunal Constitucional Español, sentencia 21/1981, de 15 de junio de 1981. Disponible en: http://hj.tribunalconstitucional.es/HJ/eu-ES/Resolucion/Show/SENTENCIA/1981/21

23 Para ejemplificar, Tribunal Europeo de Derechos Humanos, asunto Loizidou contra Turquía, demanda 15318/89, sentencia de 23 de marzo de 1995. Disponible en: http://hudoc.echr.coe. int/sites/eng/pages/search.aspx?i=001-57920\#\{“itemid”:[“001-57920”]\}

24 Así lo especifican el artículo 1.1 de la Convención Americana de Derechos Humanos y diver- 
operadores jurídicos internos les corresponde velar por los derechos en un tiempo y un espacio constitucional; ellos deben garantizar prima facie tales principios.

México se incrusta en esta interconexión normativa; como quedó señalado, con la reforma constitucional en el artículo primero, se constitucionalizan los estándares internacionales y se señala que las autoridades deben ser guardianes de estas prerrogativas. Esta situación deja atrás el monopolio para la interpretación y protección de estos derechos, que había sido celosamente guardado por los operadores jurídicos mexicanos. Mediante la interacción entre factores internos e internacionales, México pasó a sostener una posición proactiva, frente al régimen internacional de los derechos humanos ${ }^{25}$. Bartolomé Clavero-Salvador califica la reforma como una incorporación del derecho internacional de derechos humanos al cuerpo normativo del Derecho constitucional mexicano. Ahora en México, hay un Derecho internacional que es Constitución ${ }^{26}$. Para Ramón Ortega-García, esta reforma es la parcial constitucionalización de los tratados, en virtud de la gradualidad del fenómeno al requerir una nueva cultura jurídica, que en México aún no existe ${ }^{27}$.

No obstante, la reforma constitucional mexicana sufrió una mutación por parte de la Suprema Corte de Justicia y la academia constitucional al entenderla de forma muy restrictiva:

...quienes han venido promocionando en México un neoconstitucionalismo de derechos y garantías no lo reconocen en toda su dimensión cuando se lo

sos criterios de la Corte Interamericana de Derechos Humanos, como el caso AlmonacidArellano vs. Chile, entre otros. Corte Interamericana de Derechos Humanos, CiDH, Caso Luis Alfredo Almonacid-Arellano vs. Chile, Serie C-154, Sentencia de 26 de septiembre de 2006. Disponible en: http://www.corteidh.or.cr/docs/casos/articulos/seriec_154_esp.pdf

25 Natalia Saltalamacchia-Ziccardi \& Ana Covarrubias-Velasco, La dimensión internacional de la reforma de derechos humanos: antecedentes históricos, en La reforma constitucional de derechos humanos, un nuevo paradigma, 90, Miguel Carbonell \& Pedro Salazar, coords., Porrúa, México (2012). Disponible en: http://biblio.juridicas.unam.mx/libros/7/3033/3.pdf

26 Bartolomé Clavero-Salvador, Constitucionalización mexicana de los derechos humanos, inclusive los derechos de los pueblos indígenas, 33 Revista Española de Derecho Constitucional, 97, 181-199 (2013). Disponible en: www.bartolomeclavero.net/wp-content/uploads/2014/08/ REDC97-Mexico.pdf

27 Ramón Ortega-García, La constitucionalización del derecho en México, 46 Boletín Mexicano de Derecho Comparado, 137, 601-646 (2013). Disponible en: http://www.redalyc.org/articulo. oa?id=42728283006 
encuentran en casa. Por lo demás, la justicia y la politica parecen dispuestas a transitar por el camino trazado por la doctrina constitucional casera ${ }^{28}$.

En este orden de ideas, a pesar de los avances normativos para la tutela de los derechos humanos, los operadores jurídicos mexicanos no están capacitados para enfrentar el cambio de cultura jurídica a favor de la debida tutela de derechos humanos. Esta situación se refleja en los criterios restrictivos de la Suprema Corte de Justicia de la Nación.

Como se sustenta a lo largo de esta investigación, los operadores jurídicos internos de cada Estado son los que interactúan con los órganos internacionales, a fin de determinar la mejor manera de velar por los derechos humanos en ese Estado constitucional. Esta interacción no se agota en un cambio normativo, sino que exige conocer las funciones propias de la Constitución y las normas de derechos humanos ${ }^{29}$.

Es necesario reconocer el telos y la ratio de los derechos humanos en los textos constitucionales, como normas jurídicas directamente vinculantes, como límites al poder público y como principios que irradian la actuación de los particulares y la esfera pública. Esta expansión de los derechos representa un fenómeno de ubicuidad en todo el sistema jurídico que requiere técnicas de interpretación y herramientas argumentativas más allá de los criterios aislados y domésticos de los operadores jurídicos ${ }^{30}$.

28 Bartolomé Clavero-Salvador, Constitucionalización mexicana de los derechos humanos, inclusive los derechos de los pueblos indigenas, 33 Revista Española de Derecho Constitucional, 97, 181-199 (2013). Disponible en: www.bartolomeclavero.net/wp-content/uploads/2014/08/ REDC97-Mexico.pdf

29 José Ramón Cossío critica la situación mexicana al considerar que la teoría constitucional se agota en la existencia de una Constitución. José Ramón Cossío-Díaz, Teoría constitucional en México, en Teoría de la Constitución, ensayos escogidos, 466, Miguel Carbonell, coord., Porrúa, México (2012).

30 Robert Alexy, Derechos sociales y ponderación, 46, Fontamara, México (2007). 


\section{DIÁLOGO ENTRE TRIBUNALES CONSTITUCIONALES Y ÓRGANOS INTERNACIONALES PROTECTORES DE DERECHOS HUMANOS}

El fenómeno de incidencia normativa anteriormente descrito, entre los tratados y la Constitución, deriva en un diálogo entre operadores jurídicos internos e internacionales; Anne Marie Slaughter se refiere a una transjudicial communication que caracteriza las relaciones entre tribunales de dos formas distintas: horizontal y vertical ${ }^{31}$. La primera se refiere a las relaciones entre varios tribunales estatales y entre varios tribunales supranacionales. La segunda, a las relaciones entre tribunales supranacionales y tribunales estatales ${ }^{32}$.

Se debe especificar que el diálogo sugiere la idea de una interacción y no un monólogo. Hay que distinguir entre la influencia y la interacción; una es simplemente unidireccional; la otra implica una plausible reciprocidad entre los órganos encargados de la interpretación de las normas protectoras de derechos humanos. Para Humberto Nogueira-Alcalá, el diálogo interjudicial constituye un debate, una conversación o intercambio de puntos de vista entre dos o más jueces o tribunales ${ }^{33}$.

El diálogo es catalogado como un síntoma del pluralismo constitucional, Rafael Bustos-Gisbert apunta que es un tipo de comunicación obligatoria entre tribunales porque actúan en un contexto de pluralismo constitucional. No hay ya una clara unidad de interpretación, sino tantas unidades de interpretación como ordenamientos constitucionales componentes de ese pluralismo reconozcamos ${ }^{34}$. Precisamente, el pluralismo constitucional es la conditio para entender la autonomía interpretativa que corresponde

31 Anne Marie Slaughter, A Typology of Transjudicial Communication, 29 University of Richmond Law Review, 99-137 (1994). Disponible en: http://www.princeton.edu/ slaughtr/Articles/ Typology.pdf

32 Giusseppe de Vergottini, Más allá del diálogo entre tribunales, comparación y relación entre jurisdicciones, 39, Civitas, Pamplona (2010).

33 Humberto Nogueira-Alcalá, Diálogo interjurisdiccional, control de convencionalidad y jurisprudencia del Tribunal Constitucional en periodo 2006-2011, 10 Estudios Constitucionales, Chile, 2, 57-140, 58 (2012). Disponible en: http://www.cecoch.cl/docs/pdf/revista_10_2_2012/ Dialogo_Humberto_Nogueira.pdf

34 Rafael Bustos-Gisbert, XV Proposiciones generales para una teoría de los diálogos judiciales, 95 Revista Española de Derecho Constitucional, 13-63 (2012). Disponible en: http://www.cepc. gob.es/publicaciones/revistas/revistaselectronicas?IDR=6\&IDN=1287\&IDA=36348 
a cada corte constitucional pero que no opera en términos de exclusividad $^{35}$. De este modo, el diálogo implica romper con el monopolio interpretativo; Miguel Poiares-Maduro alude a: the institutional awareness en los siguientes términos: Courts must increasingly be aware that they don't have a monopoly over rules and that they often compete with other institutions in their interpretation ${ }^{36}$.

De ahí que se afirme que hay una interacción que genera un diálogo: por un lado, están los Tribunales Constitucionales o sus homólogos, los demás órganos jurisdiccionales internos; y por el otro, el Tribunal Europeo de Derechos Humanos, la Corte Interamericana de Derechos Humanos, los diversos comités de la Organización de Naciones Unidas y el Tribunal de Justicia de la Unión Europea ${ }^{37}$.

En el marco del Convenio Europeo de Derechos Humanos, el Tribunal Europeo de Derechos Humanos desarrolla una detallada jurisprudencia sobre los derechos recogidos en el Convenio y, de ese modo contribuye en el campo de los derechos fundamentales a incrementar los elementos constitucionales comunes europeos mediante una interacción. El Convenio sirve como modelo para los catálogos de derechos de muchas de las nuevas Constituciones $\mathrm{y}$, con carácter general, las normas relativas a los derechos fundamentales se interpretan conforme al convenio ${ }^{38}$.

35 Neil Walker, The idea of Constitutional Pluralism (European University Institute, EUI Working Paper Law 2002/1, 2-52, 2002). Disponible en: http://cadmus.eui.eu/bitstream/ handle/1814/179/law02-1.pdf?sequence $=1$

36 Miguel Poiares-Maduro, Interpreting European Law: Judicial Adjudication in a Context of Constitutional Pluralism, 1 European Journal of Legal Studies, 2, 1-21 (2007). Disponible en: http://papers.ssrn.com/sol3/papers.cfm?abstract_id=1134503

37 Innumerables estudios dibujan la conexión entre estos órganos; entre otros, mencionamos, Giusseppe de Vergottini, Más allá del diálogo entre tribunales, comparación y relación entre jurisdicciones, 39, Civitas, Pamplona (2010). Rafael Bustos-Gisbert, Tribunal de Justicia y Tribunal Europeo de Derechos Humanos: una relación de enriquecimiento mutuo en la construcción de un sistema europeo para la protección de los derechos, en Integración europea a través de derechos fundamentales: de un sistema binario a otro integrado, 147-168, FranCISCO JAVIER García-Roca \& Pablo Antonio Fernández-Sánchez, coords., Centro de Estudios Políticos y Constitucionales, CEPC, Madrid (2009). María Argelia Queralt-Jiménez, La interpretación de los derechos: del Tribunal de Estrasburgo al Tribunal Constitucional, Centro de Estudios Políticos y Constitucionales, CEPC, Madrid (2008). Carlos Félix PonCe-Martínez, Tribunal Constitucional y Tratados de Derechos Humanos, Egido, Zaragoza (2002).

38 El Bundesverfassungsgericht (el Tribunal Constitucional Federal Alemán), refiriéndose al Convenio Europeo de Derechos Humanos, afirmó: “... el texto del Convenio y la jurisprudencia del Tribunal Europeo de Derechos Humanos sirven, a nivel de Derecho Constitucional, como guía para la interpretación de los contenidos y fines de los derechos fundamentales y de los principios constitucionales de la Ley Fundamental, con la reserva de que ello no lleve a reducciones o restricciones de derechos individuales fundamentales previstos por la Ley Fundamental, lo 
Pero también, en sentido inverso; en primer lugar, la jurisprudencia del Tribunal Europeo de Derechos Humanos no tiene un carácter absolutamente innovador, sino que responde en muchos casos a precedentes y doctrinas nacionales, al análisis de los ordenamientos nacionales que por medio de la jurisprudencia de este Tribunal, se integran en los ordenamientos jurídicos de los restantes miembros del Convenio y; en segundo lugar, el tribunal, dado el elevado número de Estados miembros, en lugar de fijar como criterio único aquel en el que coincide la mayoría en términos matemáticos, busca los puntos de coincidencia, el "denominador común" de todos ellos, lo cual le exige una labor previa de derecho comparado entre ordenamientos nacionales ${ }^{39}$. Tal situación genera un diálogo continuo para determinar los denominadores comunes en materia de derechos humanos por los países adheridos al Convenio Europeo de Derechos Humanos ${ }^{40}$.

que no es querido por el propio Convenio". Alemania, Bundesverfassungsgericht 111, BVerfGE 111, 307, 2 BvR 1481/01, 14 October 2004. Para una mayor explicación, Christian Walter, Die Europäische Menschenrechtskonvention als Konstitutionalisierungsprozess, 59 Zeitschrift für ausländisches öffentliches Recht und Völkerrecht, ZaöRV, 4, 961-983 (1999). Disponible en: http://www.zaoerv.de/59_1999/59_1999_4_a_961_984.pdf. El Tribunal Constitucional Español emplea la doctrina del Tribunal de Estrasburgo para fijar el contenido esencial de los derechos fundamentales; por ejemplo, en cuanto a la libertad de reunión determina que, conforme a la jurisprudencia del Tribunal Europeo de Derechos Humanos, la protección de las opiniones y de la libertad de expresarlas constituye uno de los objetivos de la libertad de reunión. Así se constata en las sentencias del Tribunal Constitucional Español: 95/1988 de 25 de mayo de 1988; 301/2006 de 23 de octubre de 2006; 170/2008 de 15 de diciembre de 2008; 37/2009 de 9 de febrero de 2009; y 96/2010 de 15 noviembre de 2010. Un estudio detallado sobre el uso de los criterios internacionales por parte del Tribunal Constitucional Español se ofrece en ALEJANDRA Flores-Martínez, Un nuevo canon interpretativo de los derechos fundamentales conforme a los tratados internacionales en la Constitución española, Miguel Ángel Porrúa, Universidad Autónoma del Estado de México, UAEM, México (2013).

39 María Salvador-Martínez, Derecho Constitucional Comparado en el contexto de la integración supranacional y la globalización, 21 Teoría y realidad Constitucional, Universidad Nacional de Educación a Distancia, UNED, Madrid, 375-395, 386 (2008). Disponible en: http://e-spacio. uned.es/revistasuned/index.php/TRC/article/view/6805/6503

40 El Tribunal Constitucional Español señaló en algunos de sus fallos que: “...la jurisprudencia del Tribunal de Estrasburgo es denominador común para el establecimiento de elementos de interpretación compartidos en su contenido mínimo". España, Tribunal Constitucional Español, declaración 1/2004, de 13 de diciembre de 2004, Boletín Oficial del Estado, BOE, 4 de enero de 2005. Disponible en: https://www.boe.es/boe/dias/2005/01/04/pdfs/T00005-00021. pdf. Para ejemplificar el uso de la figura aludida, citamos la sentencia del Tribunal Europeo de Derechos Humanos, asunto Hristozov y otros contra Bulgaria, del 13 de noviembre de 2012. Disponible en: http://hudoc.echr.coe.int/sites/eng/pages/search.aspx?i=001-114492\#\{“it emid":[“001-114492"]\}. En esta sentencia, el tribunal resolvió sobre la excepción para proteger el derecho a la vida relativa a usar medicamentos no autorizados por causa de necesidad. Para determinar tal excepción y las causas para su procedencia, sustrajo elementos comunes estudiando la Constitución y la legislación búlgara, la legislación comunitaria aplicable, la legislación y la jurisprudencia de países como Alemania, Austria, Canadá, Dinamarca, España, 
En América Latina se está germinando una interacción entre la Corte Interamericana y los tribunales internos mediante el proceso de nacionalización del derecho internacional de los derechos hu$\operatorname{manos}^{41}$; la doctrina se refiere a un diálogo jurisprudencial que va hacia un ius constitutionale commune ${ }^{42}$. La Corte Interamericana en su informe anual presentado ante la Comisión de Asuntos Jurídicos y Políticos de la OEA en 2011, aludió a este diálogo jurisprudencial en los siguientes términos:

\begin{abstract}
4. Durante 2010 el 'diálogo jurisprudencial' entre la Corte Interamericana, órganos judiciales superiores a nivel interno. Este diálogo ha tenido dos efectos concretos y palpables en los últimos años. Por un lado, a nivel interno se puede verificar un creciente número de países que incorporan los estándares interamericanos de derechos humanos fijados por la Corte. Por el otro, la Corte se ve enormemente beneficiada de la jurisprudencia producida a nivel local, lo que enriquece la jurisprudencia del Tribunal y fortalece la vigencia de los derechos humanos en todos los Estados del hemisferio, ya que la protección internacional de los derechos humanos encuentra aplicación directa en el ámbito interno por parte de los tribunales locales o de cualquier órgano estatal encargado de impartir justicia ${ }^{43}$.
\end{abstract}

De esta manera, siguiendo la línea argumental expuesta y apegados a los postulados de un Estado Constitucional, no es pertinente abrigar una unilateralidad para la defensa e interpretación de los

Estados Unidos, Francia, Italia, Polonia, Reino Unido, Suecia y Suiza, entre otros. Empero, determinó que no hay denominadores comunes suficientes, aunque un número considerable de países permite el uso de estos medicamentos y especificó con claridad la procedencia de esta excepción; por tanto, utilizó la técnica del margen de apreciación a favor del Estado búlgaro y por tal motivo, la prohibición para usar medicamentos no autorizados no constituye per se una vulneración al Convenio Europeo. En este supuesto, la técnica del denominador común no es sinónimo de mayoría en términos matemáticos, sino que el criterio es buscar aspectos cualitativos que puedan configurar elementos coincidentes y suficientes para la mejor tutela de los derechos humanos.

41 Diego García-Sayán, Una viva interacción: Corte Interamericana y Tribunales Internos, en La Corte Interamericana de Derechos Humanos. Un cuarto de siglo: 1979-2004, 324-384, 325, Editorial Corte Interamericana de Derechos Humanos, San José, Costa Rica (2005). Disponible en: http://www.corteidh.or.cr/docs/libros/cuarto\%20de\%20siglo.pdf, http://www.corteidh. or.cr/tablas/diego_06.pdf

42 Eduardo Ferrer-Mac-Gregor, Interpretación conforme y control difuso de convencionalidad. El nuevo paradigma para el juez mexicano, en La reforma constitucional de derechos humanos, un nuevo paradigma, 339-429, 425 y ss., Miguel Carbonell \& Pedro Salazar, coords., Porrúa, México (2012). Disponible en: http://biblio.juridicas.unam.mx/libros/7/3033/14.pdf

43 Corte Interamericana de Derechos Humanos, Síntesis del Informe Anual de la Corte Interamericana de Derechos Humanos correspondiente al ejercicio de 2010, que se presenta a la Comisión de Asuntos Jurídicos y Políticos de la Organización, CAJP, de los Estados Americanos, OEA (Washington, D. C., 18 de marzo de 2011). Disponible en: http://www.corteidh. or.cr/docs/discursos/garciasayan_18_03_11.pdf 
derechos humanos ya recaiga en los órganos internacionales o en los internos. El protagonismo de una Corte Constitucional implica ser parte activa para proteger los derechos humanos y no estar en espera de que los órganos internacionales le indiquen en todo momento la forma de operar. La superación del monopolio en la interpretación y defensa de los derechos humanos sugiere una retroalimentación entre órganos internos y órganos internacionales protectores de estos derechos, teniendo presente que en los poderes públicos internos descansa la obligación de primeros garantes, pero no los únicos. Así, el reconocimiento de los tratados de derechos humanos y los criterios internacionales de órganos externos no significa trasladar el monopolio en los órganos internacionales. En esa lógica, como lo sostiene Diego García-Sayán, se trata de no solo influencias del ordenamiento internacional sobre el interno, sino la interacción y retroalimentación de este sobre el internacional ${ }^{44}$.

\section{LA PERSPECTIVA DEL DIÁlogo MEXICANO}

En México es interesante estudiar la inflexión en la doctrina de la Suprema Corte de Justicia de la Nación ${ }^{45}$, una vez aprobada la reforma constitucional de $2011^{46}$. Ese cambio se produjo en los argumentos vertidos en la sentencia del expediente referido dictada el 14 de julio de 2011. Vale la pena traer a colación que la Corte, anterior a esta sentencia desechó el proyecto del ministro Ramón Cossío-Díaz que propuso acatar la sentencia contra México en el caso Rosendo Radilla. Entre los argumentos vertidos en esa decisión destaca el del mismo Sergio Salvador Aguirre-Anguiano, quien señaló que la Corte Interamericana de Derechos Humanos se había extralimitado en su resolución; debido a que no consideró

44 Diego García-SAYÁn, Una viva interacción: Corte Interamericana y Tribunales Internos, en La Corte Interamericana de Derechos Humanos. Un cuarto de siglo: 1979-2004, 324-384, 328, Editorial Corte Interamericana de Derechos Humanos, San José, Costa Rica (2005). Disponible en: http://www.corteidh.or.cr/docs/libros/cuarto $\% 20 \mathrm{de} \% 20$ siglo.pdf, http://www.corteidh. or.cr/tablas/diego_06.pdf

45 México, Suprema Corte de Justicia de la Nación, Expediente varios 912/2010, de 14 de julio de 2011. Disponible en: http://www2.scjn.gob.mx/AsuntosRelevantes/pagina/SeguimientoAsuntosRelevantesPub.aspx?ID=121589\&SeguimientoID $=225$

46 Decreto 117, LXI Legislatura, por el que se modifica la denominación del Capítulo I del Título Primero y reforma diversos artículos de la Constitución Política de los Estados Unidos Mexicanos, 10 de junio de 2011. Disponible en: http://www.diputados.gob.mx/LeyesBiblio/ legis/reflxi.htm 
que cuando el Estado mexicano suscribió las convenciones había hecho reservas en materia de fuero militar ${ }^{47}$.

Pero, una vez introducida la reforma al artículo primero, la Corte definió las obligaciones concretas del Poder Judicial de la Federación en relación con la ejecución de la sentencia dictada por la Corte Interamericana de Derechos Humanos, en el caso RadillaPacheco contra México; de tal forma, que los criterios adoptados por la Corte dieron paso al diálogo horizontal entre los órganos jurisdiccionales internos y al diálogo vertical entre los órganos jurisdiccionales internos con los órganos internacionales, en busca de una protección efectiva de los derechos humanos e interpretaciones armonizadoras con los criterios internacionales. La paradigmática sentencia dejó de lado el control concentrado de constitucionalidad que recaía en el Poder Judicial Federal para dar paso al control difuso en los siguientes términos:

Es el caso de la función jurisdiccional, como está indicado en la última parte del artículo 133 en relación con el artículo 1 en donde los jueces están obligados a preferir los derechos humanos contenidos en la Constitución y en los Tratados Internacionales, aun a pesar de las disposiciones en contrario establecidas en cualquier norma inferior. Si bien los jueces no pueden hacer una declaración general sobre la invalidez o expulsar del orden jurídico las normas que consideren contrarias a los derechos humanos contenidos en la Constitución y en los tratados (como sí sucede en las vías de control directas establecidas expre-

47 El 25 de agosto de 1974, Rosendo Radilla-Pacheco fue presuntamente víctima de desaparición forzada por elementos del ejército mexicano en el Estado de Guerrero. Sus hijas Tita y Andrea Radilla-Martínez presentaron en los años 1992 y 1999 denuncias por la desaparición forzada contra quien resultara responsable; empero, las denuncias fueron enviadas a reserva por falta de indicios. En los años 2000 y 2007, Tita Radilla interpuso nuevas denuncias penales sin tener éxito, debido a falta de competencia por parte de jueces ordinarios y de investigación. Después del largo recorrido por las instancias nacionales, en 2008 la Comisión Interamericana de Derechos Humanos sometió el asunto a consideración de la Corte Interamericana, misma que resolvió el 23 de noviembre de 2009. Corte Interamericana de Derechos Humanos, CIDH, Caso Radilla-Pacheco vs. México, serie C-209, excepciones preliminares, fondo, reparaciones y costas, sentencia de 23 de noviembre de 2009. Disponible en: http://www.corteidh.or.cr/docs/ casos/articulos/seriec_209_esp.pdf. El asunto fue paradigmático por sentenciar al Estado mexicano a ejercer un control de convencionalidad ex officio entre las normas internas y la Convención Americana en el campo de sus respectivas competencias y regulaciones procesales correspondientes; se especificó que en esta tarea el Poder Judicial debe tener en cuenta el tratado como la interpretación de la Corte Interamericana. Julio Bustillos, Caso Radilla. Paradigma de la protección constitucional de los derechos humanos frente a la responsabilidad del Estado mexicano, 45 Boletín Mexicano de Derecho Comparado, 135, 989-1022 (2012). Disponible en: http://biblio.juridicas.unam.mx/revista/pdf/DerechoComparado/135/art/art3.pdf. Jorge Mario Pardo-Rebolledo, El caso Rosendo Radilla-Pacheco contra los Estados Unidos Mexicanos, 18 Anuario de Derecho Constitucional Latinoamericano, 333-346 (2012). Disponible en: http://www.juridicas.unam.mx/publica/librev/rev/dconstla/cont/2012/pr/pr22.pdf 
samente en los artículos 103, 107 y 105 de la Constitución), sí están obligados a dejar de aplicar estas normas inferiores dando preferencia a los contenidos de la Constitución y de los tratados en esta materia48.

En esta sentencia, la Corte también hizo patente el control de convencionalidad ex officio para todos los jueces internos, en un modelo difuso de constitucionalidad bajo los siguientes parámetros:

- Todos los derechos humanos contenidos en la Constitución Federal (con fundamento en los artículos 1 y 133), así como la jurisprudencia emitida por el Poder Judicial de la Federación.

- Todos los derechos humanos contenidos en Tratados Internacionales en los que el Estado mexicano sea parte.

- Criterios vinculantes de la Corte Interamericana de Derechos Humanos establecidos en las sentencias en las que el Estado mexicano haya sido parte, y los criterios orientadores de la jurisprudencia y precedentes de la citada Corte, cuando el Estado mexicano no haya sido parte ${ }^{49}$.

Con estos criterios se dejó de lado el control concentrado de constitucionalidad y se abrigó un control de convencionalidad, obligando a los jueces a utilizar los criterios de la Corte Interamericana de Derechos Humanos, CIDH, desde la primera instancia, aunque el punto de vista de la doctrina constitucional es que la Corte empujó a los jueces sin presupuestos confiables a entablar un diálogo. Como lo indica Eduardo Ferrer-Mac-Gregor, ante la multiplicidad de intérpretes de derechos humanos, en México se iniciará un interesante diálogo jurisprudencial; pero esta interacción no goza de reglas mínimas de operatividad. La concepción epistemológica de este trabajo indica que, a pesar de estos ajustes, la Corte sigue manteniendo criterios restrictivos al considerar solamente como obligatoria la jurisprudencia de la Corte Interamericana en las sentencias condenatorias para México y dejar como criterios orientadores el resto de precedentes, así como la doctrina

48 México, Suprema Corte de Justicia de la Nación, Expediente varios 912/2010, de 14 de julio de 2011. Disponible en: http://www2.scjn.gob.mx/AsuntosRelevantes/pagina/SeguimientoAsuntosRelevantesPub.aspx?ID=121589\&SeguimientoID $=225$

49 México, Suprema Corte de Justicia de la Nación, Expediente varios 912/2010, de 14 de julio de 2011. Disponible en: http://www2.scjn.gob.mx/AsuntosRelevantes/pagina/SeguimientoAsuntosRelevantesPub.aspx?ID=121589\&SeguimientoID $=225$ 
que proviene de los Comités de Naciones Unidas. La actitud de los órganos internos es pasiva, fuera de la tendencia que apunta hacia la proyección internacional de los derechos humanos con el propósito de que estos sean plenamente garantizados, sin importar a qué país pertenezca la persona que deba ser objeto de esa protección ${ }^{50}$.

Por ejemplo, la Corte Suprema de Argentina en el caso Horacio David Giroldi y otro determinó que la jurisprudencia de la Corte Interamericana de Derechos Humanos debía "...servir de guía para la interpretación de los preceptos convencionales en la medida en que el Estado argentino reconoció la competencia de la Corte Interamericana para conocer en todos los casos relativos a la interpretación y aplicación de la Convención Americana"51.

Otro ejemplo es la Corte Constitucional de Colombia en la sentencia T-568/99 que aclaró la obligatoriedad, para las autoridades internas, de las recomendaciones de la Organización Internacional del Trabajo, OIT:

...los compromisos asumidos por nuestro Estado en el plano internacional, por lo que debe insistir en resaltar que las recomendaciones de los órganos de control y vigilancia de la OIT no pueden ser ignoradas: cuando resultan de actuaciones del Estado contrarias a los tratados internacionales aludidos en el artículo 93 Superior, aunque no sean vinculantes directamente, generan una triple obligación en cabeza de los Estados: deben 1) ser acogidas y aplicadas por las autoridades administrativas; 2) servir de base para la presentación de proyectos legislativos; y 3) orientar el sentido y alcance de las órdenes que el juez de tutela debe impartir para restablecer los derechos violados o amenazados en ese y los casos que sean similares ${ }^{52}$.

Es evidente la tendencia latinoamericana para entablar un diálogo ad intra y ad extra entre los órganos jurisdiccionales; sin embargo, científicamente no se puede avalar un ius constitutionale commune en derechos humanos, por lo menos en Latinoamérica,

50 Enrique Uribe-Arzate, Una aproximación epistemológica a los derechos humanos desde la dimensión vivencial pragmática, 44 Boletín Mexicano de Derecho Comparado, 132, 1233-1257, 1244 (2011). Disponible en: http://biblio.juridicas.unam.mx/revista/pdf/DerechoComparado/132/art/art7.pdf

51 Argentina, Corte Suprema de Justicia de la Nación, Horacio David Giroldi y otro, Sentencia de 7 de abril de 1995, G. 342, XXVI. Disponible en: http://ar.vlex.com/vid/-39530907

52 Colombia, Corte Constitucional, Sentencia T-568/99, 10 de agosto de 1999. Magistrado ponente Carlos Gaviria-Díaz. Disponible en: http:/www.corteconstitucional.gov.co/ relatoria/1999/t-568-99.htm 
cuando no hay presupuestos mínimos para operar el control de convencionalidad y la interpretación conforme.

Se presume que "es asumiendo los valores de la realidad histórica preexistente - expresados a través de la voluntad del Poder constituyente - como únicamente adquieren la idea de Constitución la plenitud de su sentido" 53 y las cortes nacionales deben asumir el papel de primeros garantes. Los nuevos paradigmas para el Derecho Constitucional desembocan en el papel de los jueces e intérpretes; de tal forma que, como apunta Germán Bidart-Campos, la jurisdicción constitucional, cualquiera que sea el sistema que para ella se adopte, genera un poder judicial cargado de protagonismo ${ }^{54}$. Este protagonismo requiere adoptar una postura garante de los derechos humanos, debido a que son los jueces quienes se encargan de definir en un tiempo y espacio las libertades de los habitantes de un Estado Constitucional. Esta labor no se cumple si las cortes nacionales trasladan esta tarea a los órganos internacionales y se mantienen a la espera de sentencias condenatorias.

A mayor abundamiento, los jueces constitucionales deben contribuir a generar una cultura jurídica del debido respeto a los derechos humanos; esta tarea solo puede cumplirse mediante una exégesis jurídica de los derechos fundamentales conforme con los criterios internacionales de derechos humanos. De esta manera, se llega a sustentar que cuando de derechos humanos se trata, a los intérpretes nada les debe ser ajeno. En este sentido, los criterios internacionales se convierten en una pauta obligatoria al momento de interpretar y proteger los derechos fundamentales. Los jueces nacionales deben conocer estos criterios que para estar en disposición de generar una retroalimentación con órganos internacionales: "Los jueces constitucionales son los intermediarios principales (aunque en ningún caso los únicos) en este proceso y por tanto a ellos corresponde, en última instancia, garantizar y hacer posible dicha comunicación, tanto en su papel de intérpretes constitucionales como en el de promotores de opinión pública" ${ }^{55}$.

\footnotetext{
53 Pedro de Vega-García, Apuntes para una historia de las doctrinas constitucionales del siglo XX, en Teoría de la Constitución, ensayos escogidos, 36, Miguel Carbonell, coord., Porrúa, México (2012). Disponible en: http://biblio.juridicas.unam.mx/libros/1/114/3.pdf

54 Germán BidArt-CAmpos, Las transformaciones constitucionales en la postmodernidad, 161, Sociedad Anónima Editora, Comercial, Industrial y Financiera, EDIAR, Buenos Aires (1999).

55 Mauricio del Toro-Huerta, La apertura constitucional al Derecho Internacional de los Derechos
} 
Desde la postura de Gustavo Zagrebelsky, por el contrario, la incomunicabilidad equivale a la rotura del círculo ideal de intérpretes constitucionales. Las Cortes de justicia tienen, por así decirlo, raíces que se asientan en condiciones político-constitucionales nacionales pero tienen la cabeza dirigida a principios de carácter universal. Cerrarse a sí mismas significa solamente una cosa: predisponerse a políticas constitucionales y de los derechos humanos funcionales solamente a los exclusivos intereses nacionales ${ }^{56}$.

En suma, la posición de la Corte mexicana es aislada y en la praxis ha mutilado la reforma constitucional en materia de derechos humanos, debido a que no acepta que hay otros tribunales con auctoritas sobre la cuestión; esta reforma es ineficaz ante operadores jurídicos que defienden un monólogo interpretativo.

Humanos en la era de la mundialización y sus consecuencias en la práctica judicial, 38 Boletín Mexicano de Derecho Comparado, 112, 325-363, 351-352 (2005). Disponible en: http://www. journals.unam.mx/index.php/bmd/article/view/10593/9922

56 Gustavo Zagrebelsky, Jueces constitucionales, en Teoría del Neoconstitucionalismo, ensayos escogidos, 91-104, 95 y ss., Miguel Carbonell, coord., Trotta, Universidad Nacional Autónoma de México, UNAM, Instituto de Investigaciones Jurídicas, Madrid (2007). Disponible en: http://www.circulodoxa.org/documentos/Zagrebelsky,\%202003\%20(VIII).pdf 


\section{CONCLUSIONES}

Conforme a lo estudiado en el presente artículo se puede concluir que en el caso mexicano no hay una sólida doctrina y criterios que soporten el diálogo jurisprudencial, la interrogante por resolver es esta: ¿cuál es el grado de incidencia normativa y la vinculación para los órganos jurisdiccionales a los estándares internacionales en materia de derechos humanos? Como hemos intentado evidenciarlo, todavía esa vinculación está poco definida. Estamos entrampados, de alguna manera, en la indefinición de los parámetros del control de la convencionalidad en relación con el papel de los tribunales domésticos en el llamado control difuso de la constitucionalidad. No desconocemos el valioso auxilio de los criterios internacionales pero seguimos aduciendo que el máximo Tribunal nacional — nuestro Tribunal Constitucional - tiene la última palabra en materia de protección de derechos humanos cuando la realidad nos dice lo contrario.

Como podemos ver, es urgente desarrollar un método que respalde el diálogo entre tribunales y apuntalar con solidez los fundamentos constitucionales que soportan la incidencia normativa y fomentan el diálogo jurisprudencial. También es obligatorio determinar la manera de usar los criterios internacionales y su función en los argumentos judiciales en pro de la tutela de derechos humanos ${ }^{57}$.

$\mathrm{Si}$ a esto agregamos que el ius constitutionale commune de derechos humanos, debe abarcar todos los ámbitos competenciales de la federación que es México, ergo, no hay razones para no desarrollar la línea argumental a favor de una protección constitucional más franca a favor de los derechos humanos.

57 Un estudio interesante sobre la forma de usar los precedentes de tribunales extranjeros por parte de la Corte Constitucional colombiana puede consultarse en Lina MARCela EscobarMARTínez, El uso del precedente extranjero por parte de la Corte Constitucional colombiana, 13 International Law, Revista Colombiana de Derecho Internacional, 391-409 (2008). Disponible en: http://www.javeriana.edu.co/Facultades/C_Juridicas/pub_rev/documents/11Escobar_001. pdf 


\section{BIBLIOGRAFÍA}

\section{Libros}

Alexy, Robert, Derechos sociales y ponderación, Fontamara, México (2007).

BidART-CAMPos, GeRmán, Las transformaciones constitucionales en la postmodernidad, Sociedad Anónima Editora, Comercial, Industrial y Financiera, EDIAR, Buenos Aires (1999).

Bidart-Campos, Germán, Teoría general de los derechos humanos, Astrea, Buenos Aires (1991).

Cruz-Villalón, Pedro, La Constitución inédita. Estudios sobre la constitucionalización de Europa, Trotta, Madrid (2004).

Flores-Martínez, Alejandra, Un nuevo canon interpretativo de los derechos fundamentales conforme a los tratados internacionales en la Constitución española, Miguel Ángel Porrúa, Universidad Autónoma del Estado de México, UAEM, México (2013).

Ponce-Martínez, Carlos Félix, Tribunal Constitucional y Tratados de Derechos Humanos, Egido, Zaragoza (2002).

Queralt-Jiménez, María Argelia, La interpretación de los derechos: del Tribunal de Estrasburgo al Tribunal Constitucional, Centro de Estudios Políticos y Constitucionales, CEPC, Madrid (2008).

Schwarze, Jürgen, The Birth of a European Constitutional Order, Nomos Verlagsgesellschaft, Baden-Baden (2001).

Vergottini, GiussepPe De, Más allá del diálogo entre tribunales, comparación y relación entre jurisdicciones, Civitas, Pamplona (2010).

\section{Contribución en obras colectivas}

Brage-Camazano, Joaquín, Ensayo de una teoría general sustantiva de los Derechos Fundamentales en el Convenio Europeo de Derechos Humanos, en Integración europea a través de derechos fundamentales: de un sistema binario a otro integrado, 113-145, Francisco Javier García-Roca \& Pablo Antonio Fernández-Sánchez, coords., Centro de Estudios Políticos y Constitucionales, CEPC, Madrid (2009).

Bustos-Gisbert, Rafael, Tribunal de Justicia y Tribunal Europeo de Derechos Humanos: una relación de enriquecimiento mutuo en la construcción de un sistema europeo para la protección de los derechos, en Integración europea a través de derechos fundamentales: de un sistema binario a otro integrado, 147-168, FRANCISCO JAVIER García-Roca \& Pablo Antonio Fernández-Sánchez, coords., Centro de Estudios Políticos y Constitucionales, CEPC, Madrid (2009).

Comanducci, Paolo, Formas de (neo)constitucionalismo: un análisis metateórico, en Neoconstitucionalismo(s), 75-98, Miguel Carbonell, coord., Trotta, Madrid (2009). 
Cossío-Díaz, José Ramón, Teoría constitucional en México, en Teoría de la Constitución, ensayos escogidos, Miguel Carbonell, coord., Porrúa, México (2012).

Ferrer-Mac-Gregor, Eduardo, Interpretación conforme y control difuso de convencionalidad. El nuevo paradigma para el juez mexicano, en La reforma constitucional de derechos humanos, un nuevo paradigma, 339-429, Miguel Carbonell \& Pedro Salazar, coords., Porrúa, México (2012). Disponible en: http://biblio.juridicas.unam.mx/libros/7/3033/14.pdf

Fix-Zamudio, Héctor, Breves reflexiones sobre el concepto y el contenido del derecho procesal constitucional, en Derecho Procesal Constitucional, Eduardo FerrerMac-Gregor, coord., Porrúa, Colegio de Secretarios de la Suprema Corte de Justicia de la Nación, México (2002).

GARCíA-SAyÁn, Diego, Una viva interacción: Corte Interamericana y Tribunales Internos, en La Corte Interamericana de Derechos Humanos. Un cuarto de siglo: 1979-2004, 324-384, Editorial Corte Interamericana de Derechos Humanos, San José, Costa Rica (2005). Disponible en: http://www.corteidh.or.cr/docs/libros/cuarto $\% 20$ de\%20siglo.pdf, http://www.corteidh.or.cr/tablas/diego_06.pdf

Sagüés, Néstor Pedro, El control de convencionalidad como instrumento para la elaboración de un ius commune interamericano, en La justicia constitucional y su internacionalización: ¿hacia un ius constitutionale commune en América Latina?, 449-468, tomo II, Armin von Bogdandy, Eduardo Ferrer-Mac-Gregor \& Mariela Morales-Antoniazzi, coords., Universidad Nacional Autónoma de México, UNAM-Max Planck Institut, México (2010). Disponible en: http:// biblio.juridicas.unam.mx/libros/6/2895/15.pdf

Saltalamacchia-Ziccardi, Natalia \& Covarrubias-Velasco, Ana, La dimensión internacional de la reforma de derechos humanos: antecedentes históricos, en La reforma constitucional de derechos humanos, un nuevo paradigma, Miguel Carbonell \& Pedro Salazar, coords., Porrúa, México (2012). Disponible en: http://biblio.juridicas.unam.mx/libros/7/3033/3.pdf

Vega-García, Pedro de, Apuntes para una historia de las doctrinas constitucionales del siglo XX, en Teoría de la Constitución, ensayos escogidos, Miguel Carbonell, coord., Porrúa, México (2012). Disponible en: http://biblio.juridicas.unam.mx/ libros/1/114/3.pdf

Zagrebelsky, Gustavo, Jueces constitucionales, en Teoría del Neoconstitucionalismo, ensayos escogidos, 91-104, Miguel Carbonell, coord., Trotta, Universidad Nacional Autónoma de México, UNAM, Instituto de Investigaciones Jurídicas, Madrid (2007). Disponible en: http://www.circulodoxa.org/documentos/ Zagrebelsky,\%202003\%20(VIII).pdf

\section{Revistas}

Bustillos, Julio, Caso Radilla. Paradigma de la protección constitucional de los derechos humanos frente a la responsabilidad del Estado mexicano, 45 Boletín Mexicano de Derecho Comparado, 135, 989-1022 (2012). Disponible en: http://biblio.juridicas. unam.mx/revista/pdf/DerechoComparado/135/art/art3.pdf

Bustos-Gisbert, Rafael, XV Proposiciones generales para una teoría de los diálogos 
judiciales, 95 Revista Española de Derecho Constitucional, 13-63 (2012). Disponible en: http://www.cepc.gob.es/publicaciones/revistas/revistaselectronicas?IDR=6\& IDN=1287\&IDA=36348

Clavero-Salvador, Bartolomé, Constitucionalización mexicana de los derechos humanos, inclusive los derechos de los pueblos indígenas, 33 Revista Española de Derecho Constitucional, 97, 181-199 (2013). Disponible en: www.bartolomeclavero.net/ wp-content/uploads/2014/08/REDC97-Mexico.pdf

Constantinesco, Vlad, ¿Hacia la emergencia de un derecho constitucional europeo?, 8 Cuadernos Constitucionales de la Cátedra de Fadrique Furió-Ceriol, Valencia, 5-17 (1994).

Escobar-Martínez, Lina Marcela, El uso del precedente extranjero por parte de la Corte Constitucional colombiana, 13 International Law, Revista Colombiana de Derecho Internacional, 391-409 (2008). Disponible en: http://www.javeriana.edu. co/Facultades/C_Juridicas/pub_rev/documents/11Escobar_001.pdf

Häberle, Peter, Derecho Constitucional Común Europeo, 79 Revista de Estudios Políticos, Madrid, 7-46 (1993). Disponible en: http://dialnet.unirioja.es/servlet/ listaarticulos?tipo_busqueda=ANUALIDAD\&revista_busqueda=1166\&clave_ busqueda $=1993$

Hitters, Juan Carlos, Control de constitucionalidad y control de convencionalidad. Comparación. Criterios fijados por la Corte Interamericana de Derechos Humanos, 7 Estudios Constitucionales, Chile, 2, 109-128 (2009). Disponible en: http://www. scielo.cl/pdf/estconst/v7n2/art05.pdf

Nogueira-Alcalá, Humberto, Diálogo interjurisdiccional, control de convencionalidad y jurisprudencia del Tribunal Constitucional en periodo 2006-2011, 10 Estudios Constitucionales, Chile, 2, 57-140 (2012). Disponible en: http://www.cecoch.cl/ docs/pdf/revista_10_2_2012/Dialogo_Humberto_Nogueira.pdf

Ortega-García, Ramón, La constitucionalización del derecho en México, 46 Boletín Mexicano de Derecho Comparado, 137, 601-646 (2013). Disponible en: http:// www.redalyc.org/articulo.oa?id $=42728283006$

Pardo-Rebolledo, Jorge Mario, El caso Rosendo Radilla Pacheco contra los Estados Unidos Mexicanos, 18 Anuario de Derecho Constitucional Latinoamericano, 333-346 (2012). Disponible en: http://www.juridicas.unam.mx/publica/librev/ rev/dconstla/cont/2012/pr/pr22.pdf

Poiares-Maduro, Miguel, Interpreting European Law: Judicial Adjudication in a Context of Constitutional Pluralism, 1 European Journal of Legal Studies, 2 (2007). Disponible en: http://papers.ssrn.com/sol3/papers.cfm?abstract_id=1134503

Salvador-Martínez, María, Derecho Constitucional Comparado en el contexto de la integración supranacional y la globalización, 21 Teoría y realidad Constitucional, Universidad Nacional de Educación a Distancia, UNED, Madrid, 375-395 (2008). Disponible en: http://e-spacio.uned.es/revistasuned/index.php/TRC/ article/view/6805/6503

Slaughter, Anne Marie, A Typology of Transjudicial Communication, 29 University of Richmond Law Review, 99-137 (1994). Disponible en: http://www.princeton. edu/ slaughtr/Articles/Typology.pdf

Toro-Huerta, Mauricio del, La apertura constitucional al Derecho Internacional de 
los Derechos Humanos en la era de la mundialización y sus consecuencias en la práctica judicial, 38 Boletín Mexicano de Derecho Comparado, 112, 325-363 (2005). Disponible en: http://www.journals.unam.mx/index.php/bmd/article/ view/10593/9922

Uribe-Arzate, EnriQue, Una aproximación epistemológica a los derechos humanos desde la dimensión vivencial pragmática, 44 Boletín Mexicano de Derecho Comparado, 132, 1233-1257 (2011). Disponible en: http://biblio.juridicas.unam.mx/revista/ pdf/DerechoComparado/132/art/art7.pdf

Walter, Christian, Die Europäische Menschenrechtskonvention als Konstitutionalisierungsprozess, 59 Zeitschrift für ausländisches öffentliches Recht und Völkerrecht, ZaöRV, 4, 961-983 (1999). Disponible en: http://www.zaoerv. de/59_1999/59_1999_4_a_961_984.pdf

Zagrebelsky, GuStavo, El juez constitucional en el siglo XXI, 10 Revista Iberoamericana de Derecho Procesal Constitucional, México, 249-267 (2008). Disponible en: http:// biblio.juridicas.unam. $\mathrm{mx} / \mathrm{libros} / 6 / 2725 / 7 . \mathrm{pdf}$

\section{Working paper}

Walker, NeIL, The idea of Constitutional Pluralism (European University Institute, EUI Working Paper Law 2002/1, 2002). Disponible en: http://cadmus.eui.eu/ bitstream/handle/1814/179/law02-1.pdf?sequence=1

\section{Tratados internacionales}

Consejo de la Unión Europea, Convenio Europeo de Derechos Humanos, Convenio para la Protección de los Derechos Humanos y de las Libertades Fundamentales, Roma, 4 de noviembre de 1950. Disponible en: http://www.echr.coe.int/ Documents/Convention_SPA.pdf Roma, 4.XI.1950

Consejo de la Unión Europea, Tratado de Lisboa por el que se modifican el Tratado de la Unión Europea y el Tratado constitutivo de la Comunidad Europea, 13 de diciembre de 2007. Disponible en: http://www.consilium.europa.eu/documents/ treaty-of-lisbon?lang=es

Organización de Estados Americanos, OEA, Convención Americana sobre Derechos Humanos o Pacto de San José, CADH, San José, Costa Rica, 7-22 de noviembre de 1969. Disponible en: http://www.oas.org/dil/esp/tratados_B-32_Convencion_ Americana_sobre_Derechos_Humanos.htm

Organización de Naciones Unidas, ONU, Convención de Viena sobre el derecho de los tratados, suscrita en Viena, Austria, 23 de mayo de 1969, entró en vigencia el 27 de enero de 1980. Disponible en: http://www.wipo.int/export/sites/www/wipolex/ es/glossary/vienna-convention-es.pdf

Organización de Naciones Unidas, ONU, Pacto Internacional de Derechos Civiles y Políticos, Asamblea General en su Resolución 2200 A (XXI), de 16 de diciembre de 1966. Disponible en: http://www.acnur.org/t3/fileadmin/scripts/ doc.php?file=biblioteca/pdf $/ 0015$ 


\section{Normatividad internacional}

Alemania, Constitución de Alemania, Ley Fundamental de la República Federal de Alemania, 23 de mayo de 1949. Disponible en: https://www.btg-bestellservice. de/pdf/80206000.pdf

Argentina, Constitución de la Nación Argentina, 1 de mayo de 1853. Disponible en: http://www.senado.gov.ar/bundles/senadoparlamentario/pdf/institucional/ constitucionNac1853.pdf

Austria, Constitución, 1920. Disponible en: http://www.tresmed.es/documents/10358/31047/ Constitucion+Austria+esp.pdf

Bolivia, Constitución Política del Estado Plurinacional de Bolivia, 7 de febrero de 2009. Disponible en: http://pdba.georgetown.edu/Constitutions/Bolivia/bolivia09.html

Colombia, Constitución Política, 4 de julio de 1991. Disponible en: http://www. alcaldiabogota.gov.co/sisjur/normas/Norma1.jsp?i=4125

Ecuador, Constitución de la República del Ecuador, 20 de octubre de 2008. Disponible en: http://www.asambleanacional.gov.ec/documentos/constitucion_de_bolsillo. pdf

España, Constitución española, 29 de diciembre de 1978. Disponible en: http://www. boe.es/buscar/act.php?id=BOE-A-1978-31229\&tn=2

Guatemala, Constitución Política de la República de Guatemala, 31 de mayo de 1985. Disponible en: http://www.cc.gob.gt/index.php?option=com_content\&view=a rticle\&id $=219 \&$ Itemid $=67$

Perú, Constitución, 29 de diciembre de 1993. Disponible en: http://www.tc.gob.pe/ constitucion.pdf

Portugal, Constitución, 2 de abril de 1976. Disponible en: http://www.wipo.int/wipolex/ es/details.jsp?id=5452

\section{Normatividad mexicana}

Constitución Política de los Estados Unidos Mexicanos, 5 de febrero de 1917. Disponible en: http://www.ordenjuridico.gob.mx/constitucion.php, http://www. ordenjuridico.gob.mx/Constitucion/cn16.pdf

Decreto 117, LXI Legislatura, por el que se modifica la denominación del Capítulo I del Título Primero y reforma diversos artículos de la Constitución Política de los Estados Unidos Mexicanos, 10 de junio de 2011. Disponible en: http://www. diputados.gob.mx/LeyesBiblio/legis/reflxi.htm

\section{Jurisprudencia internacional}

Alemania, Bundesverfassungsgericht 111, BVerfGE 111, 307, 2 BvR 1481/01, 14 October 2004.

Argentina, Corte Suprema de Justicia de la Nación, Horacio David Giroldi y otro, 
Sentencia de 7 de abril de 1995, G. 342, XXVI. Disponible en: http://ar.vlex. com/vid/-39530907

Colombia, Corte Constitucional, Sentencia T-568/99, 10 de agosto de 1999. Magistrado ponente Carlos Gaviria-Díaz. Disponible en: http://www.corteconstitucional. gov.co/relatoria/1999/t-568-99.htm

España, Tribunal Constitucional Español, declaración 1/2004, de 13 de diciembre de 2004, Boletín Oficial del Estado, BOE, 4 de enero de 2005. Disponible en: https:// www.boe.es/boe/dias/2005/01/04/pdfs/T00005-00021.pdf

España, Tribunal Constitucional Español, sentencia 21/1981, de 15 de junio de 1981. Disponible en: http://hj.tribunalconstitucional.es/HJ/eu-ES/Resolucion/Show/ SENTENCIA/1981/21

España, Tribunal Constitucional Español, sentencia 95/1988, de 25 de mayo de 1988. Disponible en: http://hj.tribunalconstitucional.es/HJ/fr-FR/Resolucion/Show/ SENTENCIA/1988/95

España, Tribunal Constitucional Español, sentencia 301/2006, de 23 de octubre de 2006. Disponible en: http://hj.tribunalconstitucional.es/HJ/es-ES/Resolucion/Show/ SENTENCIA/2006/301

España, Tribunal Constitucional Español, sentencia 170/2008, de 15 de diciembre de 2008. Disponible en: http://hj.tribunalconstitucional.es/HJ/es/Resolucion/ Show/6402

España, Tribunal Constitucional Español, sentencia 37/2009, de 9 de febrero de 2009. Disponible en: http://hj.tribunalconstitucional.es/HJ/docs/BOE/ BOE-A-2009-4358.pdf

España, Tribunal Constitucional Español, sentencia 96/2010, de 15 de noviembre de 2010. Disponible en: http://www.tribunalconstitucional.es/es/jurisprudencia/ Paginas/Sentencia.aspx?cod=16219

Tribunal Europeo de Derechos Humanos, asunto Loizidou contra Turquía, demanda 15318/89, sentencia de 23 de marzo de 1995. Disponible en: http://hudoc.echr.coe. int/sites/eng/pages/search.aspx?i=001-57920\#\{“itemid”:[“001-57920”]\}

Tribunal Europeo de Derechos Humanos, asunto Hristozov y otros contra Bulgaria, sentencia de 13 de noviembre de 2012. Disponible en: http://hudoc.echr.coe.int/ sites/eng/pages/search.aspx?i=001-114492\#\{“itemid”:[“001-114492”]\}

\section{Jurisprudencia mexicana}

México, Suprema Corte de Justicia de la Nación, Expediente varios 912/2010, de 14 de julio de 2011. Disponible en: http://www2.scjn.gob.mx/AsuntosRelevantes/ pagina/SeguimientoAsuntosRelevantesPub.aspx?ID=121589\&Seguimiento ID $=225$

México, Suprema Corte de Justicia de la Nación, tesis jurisprudencial XXVIII, de julio de 2008. Disponible en: https://www.scjn.gob.mx/libreria/Novena2011Docs/ julio.pdf

México, Suprema Corte de Justicia de la Nación, tesis jurisprudencial P./J. 74/99 
de agosto de 1999. Disponible en: http://www.jurisconsulta.mx/index.php/ JurisprudenciaSCJN/ViewTesis?iD=198397

\section{Casos de la CIDH}

Corte Interamericana de Derechos Humanos, CIDH, Caso Luis Alfredo AlmonacidArellano vs. Chile, Serie C-154, Sentencia de 26 de septiembre de 2006. Disponible en: http://www.corteidh.or.cr/docs/casos/articulos/seriec_154_esp.pdf

Corte Interamericana de Derechos Humanos, CIDH, Caso Radilla-Pacheco vs. México, serie C-209, excepciones preliminares, fondo, reparaciones y costas, sentencia de 23 de noviembre de 2009. Disponible en: http://www.corteidh.or.cr/ docs/casos/articulos/seriec_209_esp.pdf

\section{Documentos, informes, reportes}

Corte Interamericana de Derechos Humanos, Síntesis del Informe Anual de la Corte Interamericana de Derechos Humanos correspondiente al ejercicio de 2010, que se presenta a la Comisión de Asuntos Jurídicos y Políticos de la Organización, CAJP, de los Estados Americanos, OEA (Washington, D. C., 18 de marzo de 2011). Disponible en: http://www.corteidh.or.cr/docs/discursos/ garciasayan_18_03_11.pdf 
